\title{
Chapter 9 \\ Modelling and Programming of Digital \\ Video: A Source for the Integration \\ of Mathematics, Engineering, and Technology
}

\section{Carlos A. LópezLeiva, Marios S. Pattichis and Sylvia Celedón-Pattichis}

\begin{abstract}
Whilst Science, Technology, Engineering and Mathematics (STEM) interdisciplinary teaching and learning in the USA K-12 education still needs greater promotion, middle school students demonstrated that they can, using low-cost, single board computers that promote the teaching of computer science (in this case Raspberry Pis), successfully engage with computer programming of digital images and videos. The context for these students' engagement was the Advancing Out-ofSchool Learning in Mathematics and Engineering (AOLME) Project. This chapter describes how the processes of design, model, and implement, supported 40 Latinx middle school students' development of computational thinking in an out-of-school setting, and how these processes promoted the genuine integrated practice and learning of technology, engineering, and mathematical concepts.
\end{abstract}

Keywords Computer programming $\cdot$ Interdisciplinary modelling $\cdot$ STEM education $\cdot$ Out-of-school environment $\cdot$ Middle school students $\cdot$ Image and video representations

\subsection{Introduction}

Instruction of Kindergarten to Year 12 (K-12) subjects, especially mathematics, is often presented in isolation. Similarly, engineering, as a subject, is rarely integrated with science and mathematics; in fact, it is predominantly absent in the compulsory school curriculum and rarely an option as an elective (Celedón-Pattichis, LópezLeiva, Pattichis, \& Llamocca, 2013). As a result, K-12 students get very little to no exposure to engineering (Katehi, Pearson, \& Feder, 2009). It is especially the case of many middle (Grades 6-8 in the USA) school students, who often have limited access to experiences and information about interdisciplinary knowledge, such as science, technology, engineering, and mathematics (STEM) fields. Unfortunately, evidence reveals that this omission often translates into: student misconceptions of what STEM

C. A. LópezLeiva $(\varangle) \cdot$ M. S. Pattichis · S. Celedón-Pattichis

University of New Mexico, Albuquerque, NM 87131, USA

e-mail: callopez@unm.edu

(C) The Author(s) 2019

B. Doig et al. (eds.), Interdisciplinary Mathematics Education,

ICME-13 Monographs, https://doi.org/10.1007/978-3-030-11066-6_9 
fields are about; the exclusion of STEM careers from students' future goals (Mooney \& Laubach, 2002); and the view of school subjects as scattered, artificial, knowledge, with little relevance to their lives (Reeves, 2011). Current statistics in the USA reveal misconceptions of STEM fields, for example, that learning technology means knowing basic computing and internet browsing, or, that STEM fields are too difficult, boring, or exclusionary, especially to students from minority backgrounds (Hossain \& Robinson, 2012). Not surprisingly, the under-representation of ethnic groups and women in STEM fields in the USA is evident (Dowd, Malcom, \& Macias, 2010; Landivar, 2013; Syed \& Chemers, 2011) and so is the low enrollment of high school students in STEM academics, as well as their decreasing interest of staying in school (Hossain \& Robinson, 2012; Rogers, 2009). Alarmingly, while there is an increasing demand for computing graduates in the USA (Defense Advanced Research Projects Agency DARPA, 2010), there is a declining student enrollment in Computer Science degrees, with high dropout, and failure rates, during the first and second years in the programme (Beaubouef \& Mason, 2005). Correspondingly, Latinx high-school and college students in the USA have faced limited success in, and access to STEM fields, the highest dropout rates, and the lowest graduation percentages (Chapa \& De La Rosa, 2006; Ortiz, Valerio, \& Lopez, 2012).

Consequently, there is a strong need for the student population in general, specifically for minority ethnic groups, and women, to develop a scientifically literate citizenry, and inspiration to pursue STEM fields. The integration of science and engineering concepts and practices with mathematics need to become more evident to students at schools (Shaughnessy, 2012). Current educational frameworks, like the Common Core State Standards for Mathematics, CCSS-M (National Governors Association for Best Practices \& Council of Chief State School Officers, 2010), and the Next Generation Science Standards (NGSS Lead States, 2013) have recommended such integration. Interdisciplinary approaches reach beyond by providing students with learning experiences that, not only include tasks and problems solved through subject integration, but also that depict more genuine applications of the topics learned. In this chapter, we describe the participation of USA middle school, predominantly Latinx students, in the Advancing Out-of-School Learning in Mathematics and Engineering (AOLME) Project, and how, through a model-eliciting activity (MEA) (Lesh, Hoover, Hole, Kelly, \& Post, 2000) of programming digital videos, students engaged in technology, engineering (specifically computer programming), and mathematics practices. Analysis of students' practices and reasoning, using lowcost, single board computers designed to promote teaching computer science, called Raspberry Pis, yielded a three-stage process (i.e., designing, modelling, and implementing) for the creation of such projects.

The design, model, and implement processes, describe students' reasoning through MEAs and how they developed their videos from original sketches, using paper and pencil, all the way through the programming and sharing of their final projects. Through design students generated the content, or the stories, characters, and images to be included in their digital video. During modelling with mathematics, students mathematised the video images using two-dimensional array and their colours by using binary and hexadecimal numbers. In implementing, they coded the 
mathematised information of the video. The coding process involved the use of an actual programming language (Python in a Linux environment) to program and represent the images of the digital videos. In this chapter we will describe, through samples of students' work on MEAs, how the designing, modelling with mathematics, and implementing processes, evolved. We argue that these processes are integrative for the teaching and learning of technology, engineering (computer programming), and mathematics, especially when such MEAs include students' creativity, interests, and current knowledge.

\subsection{Methods}

The Advancing Out-of-school Learning in Mathematics and Engineering (AOLME) project was initially developed during a three-year period, with the initial participation of a total of 50 middle school (grades 6-8) students, predominantly Latinx, who attended one of the four 10-12 week programmes. In this manuscript, we analyse the processes that took place during the creation of the final projects. The final projects were set up through a MEA framework. Given the quality of student engagement documented through our participant observation, we chose to focus exclusively during the three sessions where students worked in the final project rather than the other sessions where students learned about and practice the curricular content. Thus, the final projects represent an application of what students learned in the project to program collectively a colour video from the pixel level. The data corpus for this study included the three videotaped sessions of students groupwork during the four AOLME programmes. In each programme students worked in teams, with total of about 5 teams per programme. Other data also included student interviews and facilitators' field notes.

Based on a participatory, situated engineering learning perspective (Johri \& Olds, 2011), we analyzed the data knowing that the development of engineering and mathematical identities is parallel to the learning process (Litzinger, Hadgraft, Lattuca, \& Newstetter, 2011; Martin, 2006) and that student learning is relational (Domínguez, LópezLeiva, \& Khisty, 2014). A saturated comparative, and contrastive analytical data process (Miles \& Huberman, 1994) yielded that the creation of video representations resulted from a three-fold process (i.e., design, modelling, and implementation) that simultaneously combined students' mathematical and engineering perspectives with students' current resources and understandings, since students drew from own interests and collectively-generated ideas to creatively develop and program videos using Python code. To describe this process, we selected the work of a specific team of students to present a storyline of how collectively students engaged in the design, modelling, and implementation of videos. 


\subsection{The AOLME Project}

The Advancing Out-of-school Learning in Mathematics and Engineering project, AOLME sets out to motivate middle school students, predominantly Latinx, in urban and rural settings, to engage in more meaningful experiences in Technology, Engineering, and Mathematics fields, and to increase their interest to pursue related careers. AOLME is currently (see aolme.unm.edu) implemented in two schools (rural and urban) in the Southwest of the USA, with a total of 40 students yearly. Through an integrated mathematics and computer engineering curriculum, AOLME focuses on authentic learning experiences about the work of computer engineers, such as computer programming, engineering design, and mathematical concepts. Student learning and attitudes toward and interests in Technology, Engineering, Mathematics, and computing careers encompass the focus of the research project. AOLME's ultimate goal is to first finalize the curriculum, and then adapt it to be implemented as an elective course, during regular school time.

The AOLME project was developed through the recommendations of prior research (Celedón-Pattichis et al., 2013) that suggest interdisciplinary approaches to support greater learning opportunities. For example, in bilingual education the integration of content areas into a lesson, or unit, is considered as a meaningful approach, as students get to experience and learn the target concepts in a contextualised and interconnected environment that provides a set of generative ideas that support the development of conceptual understandings, discourses, terminology, practices, and knowledge pertinent to and needed in that context (Pérez \& Torres-Guzmán, 2002). This integration must extend also to the interdisciplinary participation of experts from different fields, such as, educators and engineers. Unlike AOLME, prior efforts attempting to include engineering, in earlier grades, have mostly been done by people who have been trained in the engineering field and not by people with specific training and research in education (Johri \& Olds, 2011; Litzinger, Hadgraft, Lattuca, \& Newstetter, 2011).

The mathematics and engineering curriculum prepares students through a twelvesession (2-3 h each session) programme to design and implement digital image and video representations. The curriculum includes pencil-and-paper, modelling, and computer-based tasks. Topics covered introduce students to building a basic computer system; using co-ordinate systems to represent images and videos; and moving across number systems (e.g., binary and hexadecimal) to represent, model, and program their images and videos. The final project requires students to develop their own designed images and video. Initially, AOLME used Matlab, since it represents the dominant computing environment for applied mathematics and numerical analysis (Strang, 2007). The high cost of Matlab led us to select Python as the free and opensource alternative that is also very easy to install and use for scientific computing applications (Jones, Oliphant, \& Peterson, 2014). Python is a popular programming language and is freely and openly available on all computing platforms. We also selected the Raspberry Pi computer, since it is a low-cost, single board computer that supports Python, Linux languages, and Mathematica software (e.g., Canelake, 2011). 
Furthermore, AOLME developed Python libraries of image and video processing functions that have allowed us to provide the functionality needed for the project. The video programming process is also linked to a modelling process that we describe next.

\subsection{Mathematical Modelling}

Mathematical modelling presents a context with great potential for the integration of technology, engineering, and mathematics. This approach aims to motivate schools, teachers, and students to engage in mathematics modelling that integrates mathematics with purposeful applications. In the case of AOLME, mathematical modelling is integrated with engineering, through the development of digital images and video. On the one hand, digital image and video representations provide a learning context in which engineering and mathematical concepts blend naturally, and where students are challenged to learn the underlying mathematical structure and computer programming concepts, required for practical implementation. On the other hand, AOLME students have demonstrated that they are highly motivated to participate in activities that include the development of digital images, and videos, that they can also share with their friends. Thus, our approach represents a balanced context for motivating, and yet challenging students to engage in the practice of modelling with mathematics.

Previous studies have described the benefits of modelling with mathematics, which represents relationships found in everyday life in the mathematical system by using mathematical conventions and symbols (Lesh \& Doerr, 2003). Thus, Modelling is a way for students to re-invent or "formalise their informal understandings and intuitions" (Gravemeijer, Cobb, Bowers, \& Whitenack, 2000, p. 237) and rehearse mathematical concepts (Lesh \& Doerr, 2003). Modelling helps students learn mathematics since "learning it means doing mathematics, in which solving real-life problems is essential" (Gravemeijer, 1997, p. 332). Then, modelling is a mathematical rediscovery process of patterns and rules in authentic situations. It represents a high level of cognitive demand for students of doing mathematics (Stein, Smith, Henningsen, \& Silver, 2000). The modelling context matters to students since if they know the context to be modelled, the mathematical descriptions will flow more easily (Gravemeijer et al., 2000; Lesh \& Doerr, 2003). In mathematics education in the USA, the Common Core State Standards for Mathematics (CCSS-M) initiative, defines Modelling as "the process of choosing and using appropriate mathematics and statistics to analy[s]e empirical situations, to understand them better, and to improve decisions" (National Governors Association for Best Practices \& Council of Chief State School Officers, 2010, p. 72). 


\subsubsection{Our Model-Eliciting Activities (MEAs) Framework}

Drawing on Lesh, Hoover, Hole, Kelly, and Post (2000), we use the model-eliciting activities (MEAs) framework to refer to activities that encourage students to develop and test models. On the one hand, MEAs help students understand that mathematics is more about doing, than just seeing. On the other hand, MEAs also support the assessment of students' higher-order understandings of computational thinking by developing models that reveal their interpretation of, thinking about, and mathematisation of images and videos. Thus, the model-eliciting activity framework supports AOLME work by promoting student learning and engagement in Technology, Engineering, and Mathematics practices, and by documenting how students reveal and reflect on their thinking through the modelling process. MEAs have informed our understanding of student' evolving learning and knowledge by being able to link the final products and intermediate solutions of the tasks with what the students documented and thought during the creation of these products. MEAs are developed based on the following principles:

1. Model Construction

2. Reality

3. Self-Assessment

4. Construct Documentation

5. Construct Shareability \& Reusability, and

6. Effective Prototype (Chamberlin \& Moon, 2005; Lesh, Amit, \& Schorr, 1997, 2000).

AOLME includes only one model-eliciting activity at each curricular level. Each accounts for about $30 \%$ of the time that students spend during a specific level of the AOLME curriculum. For example, during Level 1 (included in this chapter), students design, and program, a digital video (black and white or colour from the pixel level), collectively. The process starts with the generation of a story for the video that represents the group's identity and interests. Then, they model with mathematics the images or frames in the video and translate these models into an intermediate code that helps them to program and display the envisioned original story (see later Figures of students' work). The model-eliciting activity is open-ended to support students' input regarding their prior skills, knowledge, and needs, through which they design and develop a product that reflects their personal interests. Throughout, students document these processes using different formats (e.g., paper and pencil, digital files, or scripts of their coding) that describe how their ideas and plans evolved over time. As a result, the whole process asks students to develop collectively explanations and constructions by "repeatedly revealing, testing, and refining or extending their ways of thinking" (Lesh et al., 2000, p. 597). MEAs simultaneously integrate student participation in, and learning of, computational thinking, mathematics, art, and computer programming. Because students constantly revise and reason about their models, they actively and genuinely use discourse related to computational thinking, computer programming, and related mathematical concepts. Because "students develop mathematics [Technology, Computer, and Engineering] concepts as 
they use them discursively to construe meaning" (Schleppegrell, 2007, p. 148), students engage in and develop interdisciplinary discursive (i.e., thinking, talking, and doing) practices through their work in projects, or MEAs.

\subsection{Findings}

The designing, modelling, and implementation phases comprise a set of non-linear processes that are continuously linked. These connections are especially evident when students debug the program interactively based on the output of their work. This portrayal informs them about alignment with their design, modelling with mathematics, and the implementation. Thus, student-generated videos, or their final projects, blend together the designing, modelling, and implementation processes in the development and refinement of student goals.

\subsubsection{The Process of Designing}

Designing relates to the student generation of content and ideas of the stories and characters that they include in their digital images and video. The design process emerges from students' ideas as sources for modelling with mathematics and supports their authoring of visual narratives. This process engages students in trying out new identities (Gee, 2003) through engagement in new practices. It allows them to take ownership of the modelling process and creation of the video, not only because they create it, but also because the source of the project itself includes their own ideas. We believe that this situation represents a Realistic Mathematics Education approach, because we witnessed how students' attitudes during Modelling and programming "went from not caring much to actually being genuinely interested in the topic, especially as we started working with video" (Facilitator's Fieldnotes, Summer 2013). Also, students "were proud of what they did and they enjoyed showing others and watching it themselves. They were a lot more interested to find out how it works" (Facilitator's Fieldnotes, Spring 2014). We believe that student-centred video creation is a source of student real interest in mathematics and engineering applications. Videos represent students' own ideas and self-expressions that are portrayed through digital image and video representations. As a result, the design of videos as an MEA, supported extensive reasoning, collaborative, and spontaneous creative work.

\subsubsection{Extensive Collaborative Work}

Since the video was to represent a team, the process of conceptualising the video was often a collaborative process, where the brainstorming of own ideas and shared 
interests and experiences in the team, were the sources of creativity and storylines. Teams determined their team names at the beginning of the programme, and, as they shared being part of the same team, a shared collective identity around that name emerged and influenced the creative process. In the case of the Eagles team, students used a picture of a frog during the session on colour images. This frog was seen as cute and funny. The team brainstormed about the video topic, and the discussion evolved as follows:

Dora: We can probably do a car, like a frog jumping.

Jonathan: I like the frog [searching in mobile phone]

Dora: [continues story] ...into a hood, changing its colours like a chameleon and then jumps into the car and then it hits the car and then it jumps to another car and it gets into a wall and the car explodes! [expands arms].

Alejandro: Yeah, we have to make it like really ...

Juan: But, the frog dies! [whines and smiles]

The interaction above provides evidence of a participatory and shared process of generating the storyline of the video. While some aspects changed, most of these topics remained throughout the completion of the project. After agreeing with the story, the division of labour to complete the work for the video was as shared as the development of the storyline. The interaction below illustrates the negotiation of this distribution of character designs.

Dora: Let me see how the frog is (i.e., looks) [says to Jonathan].

Juan: I'll do the car.

Alejandro: So here is the frog [shows grid with frog to Juan].

Juan: [nods]

Alejandro: We need the jumping frog, then we need the car, and I think that's it.

Alejandro: [to Dora] This should be yellow [points to frog's mouth], this should be black [frog's eye], is that right?

Team members consulted each other throughout the image design process, on the colours and the tasks to complete the video story. The openness of final project as a MEA helped teams capitalise on members' diverse interests and skills and collaborate as a result. When issues arose in the design process, the collective brainstorming, collective support, and creativity increased as described next.

\subsubsection{Spontaneous Work and Creativity}

The design process promoted shared leadership and team-work. The energy around the teams was characterised by smiles, dedicated work, intense thinking processes, consultation, investigation, reasoning, communication, and creativity. Figure 9.1 depicts such an environment.

The design of the car for the frog encompasses this collective and creative process. While initially the idea of having the frog in a car was clear, what seemed unclear was the size and look of the car and the frog. Another issue, or constraint, related 


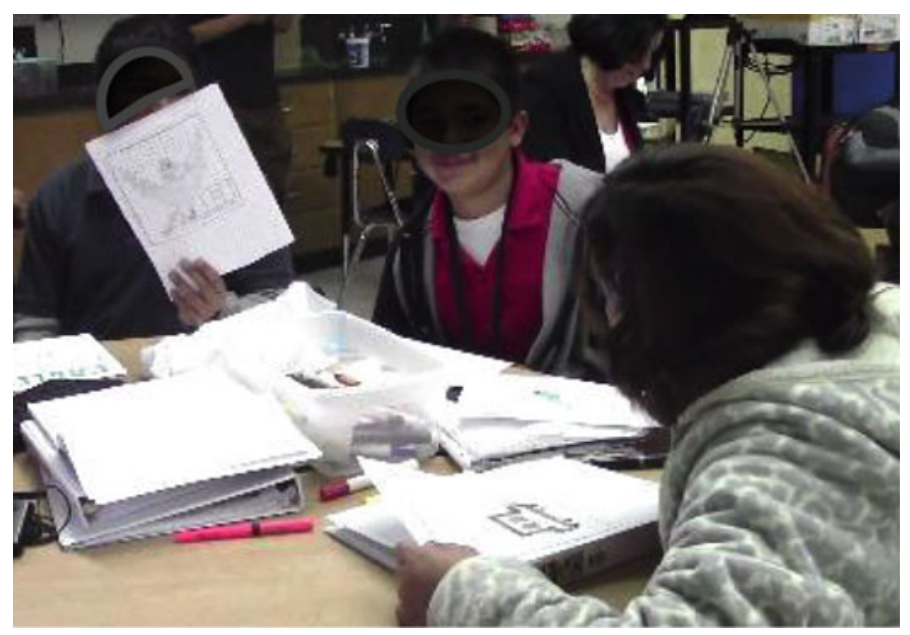

Fig. 9.1 Eagles team working on the initial design of their video frames
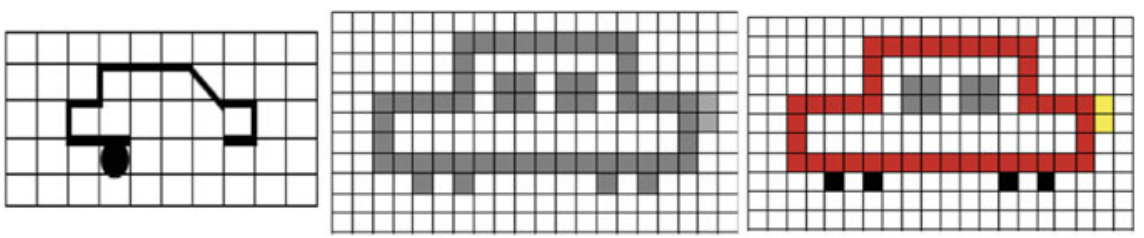

Fig. 9.2 Initial car designs

to these elements, was the size of the matrix, or number of pixels, for each video frame. Figure 9.2, depicts the evolving shape of the car. The picture on the left was the first car design that was changed since the wheels, the front side of the car, and the windshield did not include complete pixels. In fact, this image is just an outline image rather than a pixellated image. Then, the car in the middle came to be a design that aligned better to these constraints. Once the car aligned with the constraints of the design for pixels, Dora selected colours for the car (picture on right).

Nevertheless, the frog design presented a challenging task because it needed to be small enough in relation to frame size to allow other aspects of the story to be included, like the frog movement of jumping onto and driving the car, but still the image needed to include enough details to be identified as a picture of a frog. Thus, once the design of the frog was completed, it affected the design of the car. Figure 9.3 on the left depicts the final frog design on paper. The car picture in the middle shows how the car shape above was enlarged to fit the frog inside. The new design seemed inefficient in several ways as it only had 5 pixels of height and the frog was 6 pixels tall. Also, the frog needed to jump into the car, so the car design seemed limiting to the story and the frog movement. In collaboration with the team, Dora developed a new car design, a convertible (picture on the right). This design perfectly fit the story 


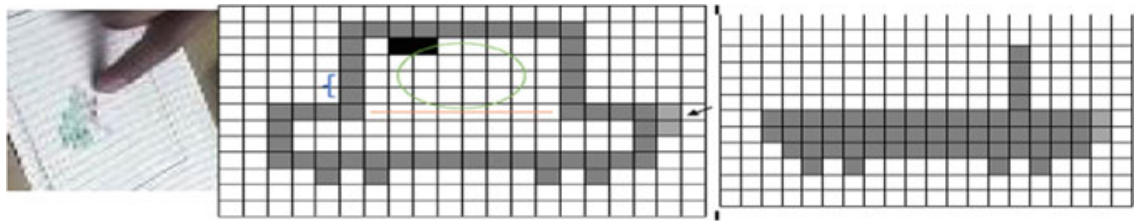

Fig. 9.3 Relationship between the frog and the car designs

and size of the frog. The collection of car designs shows a negotiated, collective, and creative process of the design of the most efficient image through the interplay of the team's story, goals, mathematical reasoning, and communication, and under the constraints of developing or creating pixellated images.

While the team distributed the design of elements (objects, frames, or sequence of images in the story) among their members, these elements needed to come together in a cohesive way to align to the common vision and goal of the video. In this process, negotiation of differences, reciprocal support, measuring, shared reasoning, and creativity, were spontaneous processes in the team's effort of design. Students perceived their videos as a real activity that demanded applications of mathematical and engineering concepts. Under this lens, the sequences of frames, or digital images, of the videos represented meaningful sources for student engagement and the promotion of computer programming and mathematical practices such as modelling with mathematics.

\subsubsection{The Process of Modelling with Mathematics}

While designing is also linked to measuring the shape and size of objects given a coordinate plane, the second process, to model with mathematics, refers to a digital modelling process, or the binarisation (black and white- or 0 and 1, or hexadecimal representations of colours) of the images. Using two-dimensional array representations or a coordinate plane, students generated images, by using grid paper and pencil. Now, the next step is to mathematise, or model, these images from the pixel level by indexing specific location and colour of the squares or pixels, on the coordinate plane. The images in each frame were to be transformed throughout the video, so that each frame would continue, visually and conceptually, the storyline that students envisioned. The transcript of the interaction below presents how the team continued working together to organise the order of the frames, as well as to mathematise, and index the colours, by using hexadecimal numbers. Specifically, Juan was working with the facilitator on the frame where the frog crashes the car against a wall.

Dora: $\quad \mathrm{OK}$, this is one, two, this one is three, this one is four [writes a number to order the frames]. 
Fig. 9.4 Mathematising the frog on multicoloured car

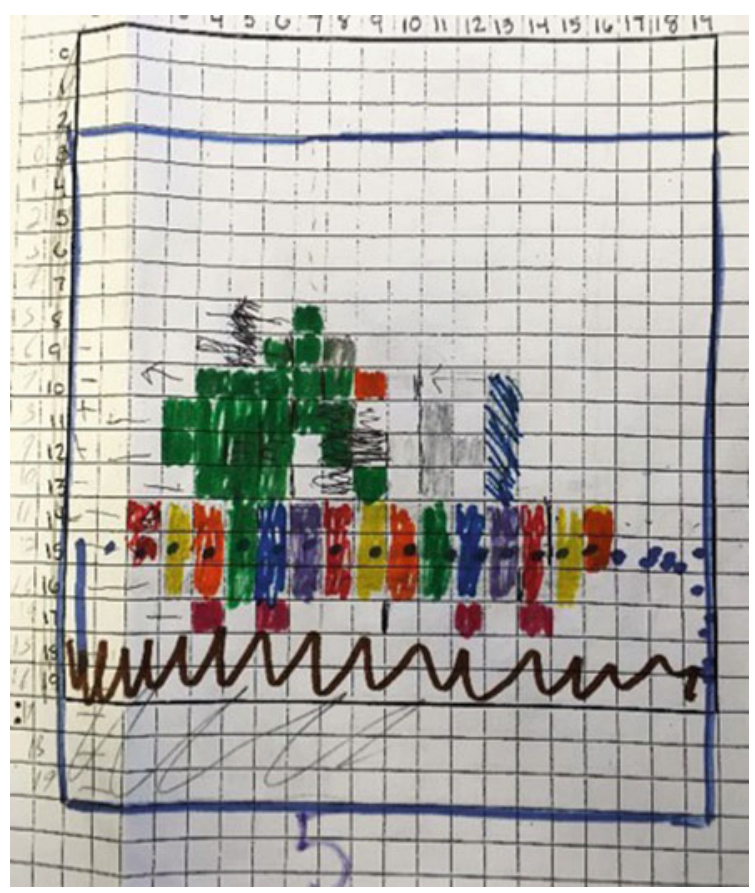

Juan: The variables we'll use for the colours are: $\mathrm{G}=$ green, $\mathrm{R}=$ red, $\mathrm{GR}=$ grey.

Alejandro: What colour is for the brick?

Juan: $\quad$ Red? ... the orange is F, F, A, D.

Alejandro: A, D

Juan: Zero, zero

Alejandro: Zero, zero, ok.

Juan: $\quad$ Brown is ninety-nine

As Fig. 9.4, shows, students numbered each frame with the goal of identifying specific pixels. This coordinate system would ease the location of the pixels to enter the previously designed images. In this example, one can see how at this point, the car was conceived as multicoloured, a fact that was changed later on into a monochrome car to ease the shifting colours features of the frog. For the indexing of the location of the pixels in the car, one can see how students used black dots to mark the exact location. They also used arrows to mark the number of pixels that the frog was away from the border of the frame. Notice how the frame was lowered to centre the frog.

To introduce and conclude the video, the team also designed an image of an eagle to show ownership of the video. The features of the design of the eagle became more evident to the group through the Modelling with Mathematics process, as students noticed that the wings and body of the eagle were symmetrical. This discovery helped them simplify the work by only indexing a half of the eagle's co-ordinates. 
Fig. 9.5 Frame one of the Eagle team's video: a symmetric eagle

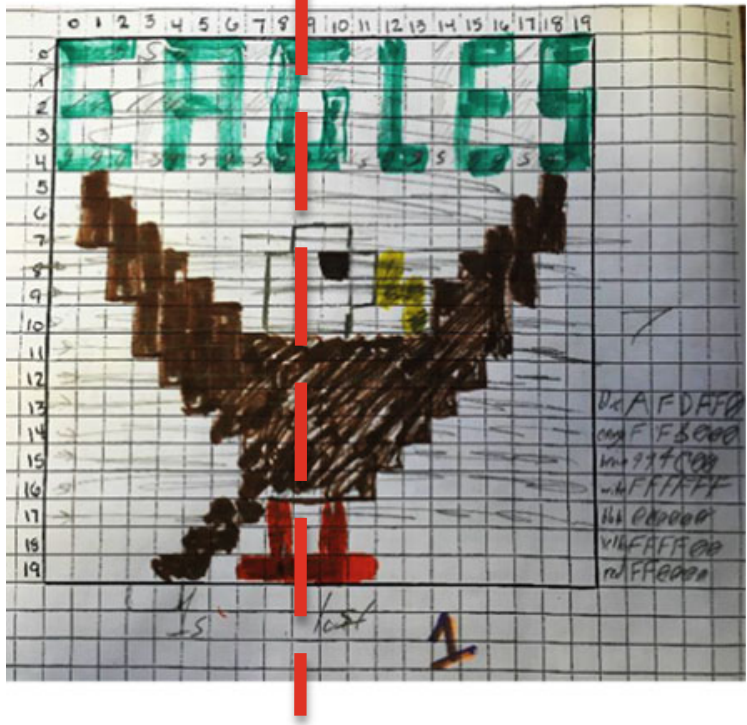

Figure 9.5 displays the line of symmetry that students identified. At the same time, students listed the colours with the corresponding hexadecimal numbers at the lower right corner of Fig. 9.5 to ease the entry data for this video frame. Students simply entered half the codes for the wings, legs, and blank spaces around it and then copied it. Then, students added data details that varied from the symmetry pattern to complete full eagle image. As a result of student investment through the development of their own ideas of images and expression of who they were as a team, students felt encouraged not only to complete the look of the project in the best way possible, but also to notice and strive for mathematical and computer programming syntactic accuracy, so their project could be what they had envisioned. These aspects became evident in the implementation process.

\subsubsection{The Process of Implementing}

The last process, to implement, refers to developing the coding of the representations of the digital images, and video, by using two-dimensional arrays. This process involves a more direct connection to computer programming by programming with Python to represent digital images and video. In terms of modelling with mathematics, this process includes a mathematical component, coding for colours, which is directly integrated in computer science and engineering. Figure 9.6 depicts how students programmed the frog to shift colours as a chameleon, which took a complicated pathway. In consultation with an AOLME program facilitator, the Eagles team used 


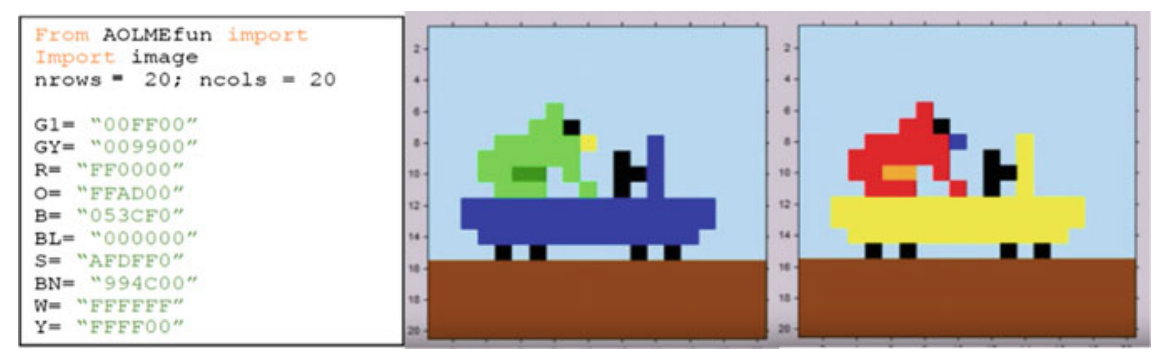

Fig. 9.6 Coding the chameleon frog

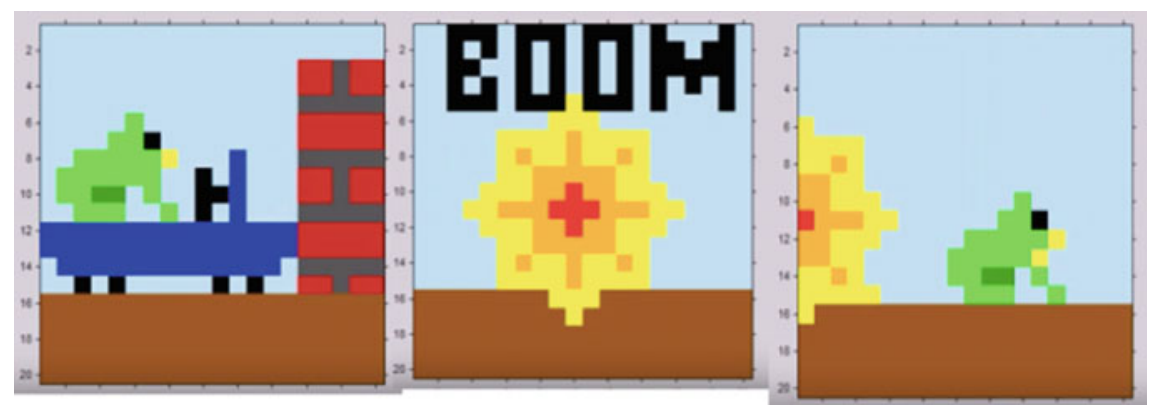

Fig. 9.7 Design of the crash through implementation

variables to ease the code entering process for each of the colours in the frames, especially for frames wherein the frog was at the same location, but needed different colours. Students created a variable for each colour to avoid repeating the color codes in the program. The image on the left describes the Python codes the team used to define each variable. The images in the middle, and on the right side, depict the shifting colours of the frog. For this to happen, the team simply copied the same Python color representation from the previous frame and, to change the colours, the team simply redefined the colour variable definitions each frame. In this way, the team saved time and effort and, at the same time, this process reveals the level of sophisticated understanding that the team managed to achieve. Additionally, this example describes the relationship and fluid movement across the design, model, and implement processes.

Another aspect that became important to the team was the frame-rate or speed of displaying the video, so that the shifting of colours and the crash would look as desired. The team decided, collectively, on this feature through trial of several speeds until consensus was reached. As Fig. 9.7 portrays, the Eagles team broke down their story into frames that told the story in the most efficient way. The team increased cohesion of the frames by adding a common background across frames (brown ground and blue sky). Such features became more evident as the team ran, or implemented, their video. This feedback process describes the interconnected functions of the design, model, and implement processes. The design can be changed 
and improved in the implementation. At times, the implementation revealed issues of the modelling.

As a result, we view the design, model, and implement processes related to the nurturing and development of computational thinking. The processes (design, model, and implement) observed in the MEA for the development of a digital video at the pixel level, refer to specific stages of thought, social support, and emotional engagement. Together, these elements supported student computational thinking. Further, this computational thinking seems to make sense to the students because the whole process arises from the students' ideas, interests, needs, and goals. The language of computers and mathematics become tools to achieve these goals. In the process, students engage in, and learn, engineering and mathematical discourse practices. As students constructed and made meaning of their personally-relevant projects, they willingly nurtured their use of the language and the ways of thinking needed to engage in the required practices and concepts (Schleppegrell, 2007) to program and model with mathematics their digital colour images and videos. You can watch the video the Eagles team developed by visiting the following link: https:// www.youtube.com/watch?v=XJIUTALGaW0.

\subsection{Discussion}

The design, model, and implement processes, during a MEA, provide a promising integrative combination for the teaching and learning of mathematics and engineering, and computational thinking. Computational thinking processes emerge through a synergy between engineering design, mathematical modelling, and computer programming and student input. Computational thinking (CT) is defined as:

$\mathrm{CT}$ is an approach to solving problems in a way that can be implemented with a computer. Students become not merely tool users but tool builders. They use a set of concepts, such as abstraction, recursion, and iteration, to process and analyse data, and to create real and virtual artifacts [sic]. CT is a problem-solving methodology that can be automated and transferred and applied across subjects (Barr \& Stephenson, 2011, p. 52).

In relation to the design, model, and implement processes, computational thinking becomes especially significant when the process includes MEAs, or projects, that address students' creativity, interests, and current knowledge, such as video and image representations. This combination promotes the development of learning and ownership of technology, engineering, and mathematical practices and related identities. In this way, a genuine and meaningful engagement with the practices also nurtures a new lens of seeing oneself-new identities, possibilities of being-as creators, programmers of videos, modellers, and users of mathematics who translate their ideas and stories into numbers and digital representations. As a result, we learned that all middle school Latinx students in the programme successfully engaged in computational thinking and STEM practices. Further, images and video provided a real, and meaningful, context for students to learn about, and improve, 
programming skills. Also, collaboration in the teams seemed to be nurtured when student participation took place in an activity that was interesting to all, and in which the responsibility and authorship of the project were distributed among all participants. Finally, the discrete work that took place in each process (design, model, or implement) and the linear connections to the prior, or the next, process evolved when the understanding of a practice was clear and shared. Complex connections among the processes emerged through questions and interests that turned into a collective problem posing, or problem-solving task, that required the activation and interaction of all the processes. Greater analysis of the link between student participation, engagement in STEM practices, and identity development, from the perspective of the students, would be illuminating. Exploration of collective problem solving through the complex interaction of the design, model, and implement processes provide further insight into mathematics, computer programming, and student thinking and learning.

Our society is evolving at a fast pace, where technological and cultural changes are evident. Under such demands, a transformative pedagogy is needed to support human development that grants greater access to current needs and re-humanizes mathematics (Gutiérrez, 2018). This pedagogy acknowledges power distribution, and accordingly, emancipates students from relegated positions through access to knowledges, opportunities, and new channels, that provide paths to navigate and engage meaningfully in technological and cultural forces that aim at positive impact on their communities (Code for All, n.d.; Cope \& Kalantzis, 2009; Johri \& Olds, 2011; Kalantzis, 2006; Kalantzis \& Cope, 2005) and selves. Thus, we argue for a pedagogy that sustains students' cultural and linguistic competence of their communities, while also offering access to dominant cultural competence (Paris, 2012). This transformative, sustaining, and responsive STEM pedagogy-while sensible to students' cultural and linguistic backgrounds-also envisions and supports students as creators and producers, rather than simply consumers of meaning and technological knowledge and artefacts.

Although the Next Generation Science Standards describe computer programming, or coding as part of the curriculum in the U.S. (NGSS, 2013), through our experiences and literature, we have corroborated and witnessed the limited access that middle school students from minoritized groups have during regular school time and as part of the curriculum. Instead, school districts often reinforce remedial curricula and programs for schools with this population. Thus, these students end up having little to no access to knowledge and practices such as computer programming (Chapa \& De La Rosa, 2006; Katehi et al., 2009; Mooney \& Laubach, 2002) and the related mathematics. Elective courses and after-school programs are main sources of this limited access. Additionally, such programs are often led by experts outside of education fields (Johri \& Olds, 2011; Litzinger et al., 2011).

In contrast, as described above, we have also witnessed how Latinx middle school students can engage successfully in computer programming and related mathematics practices. Through the design, model, and implement processes, we established how students engaged with computer programming and computational thinking. In fact, programming is described as a decomposition process (Szlávi \& Zsakó, 2017). Stu- 
dents, who self-selected to be in AOLME, solved the problem through the complex process of designing and programming images and videos through abstract thinking by modelling, and de- and re-composing the images (digital and on paper) through the analysis and development of patterns, recursion, symbolic representation, and algorithmic thinking (Chamberlin \& Moon, 2005; Lesh et al., 1997, 2000; Lesh \& Zawojewski, 2007; Psycharis \& Kallia, 2017; Wing, 2006) to implement their video projects.

Moreover, these projects were linked to student ideas and topics that were meaningful to them, so through programming they expressed human thinking and likes (Pea, Kurland, \& Hawkins, 1985). Then, while these practices were new to students, they appropriated these practices by using their home language, collaborating in teams with one another and their facilitators, and creating videos with content meaningful to themselves, their peers, and families. Simultaneously, students gained knowledge of practices that the facilitators-mostly engineering college students - identified as non-existent in their K-12 experience. Thus, AOLME experiences provided students with opportunities to see what they can do, as well as an improved understanding of what they need to know to go to college, especially for studying Engineering and Computer Science, where programming is essential. Given current technological demands in society, goals that students described for their future, and student opportunities to access knowledge that addresses both demands, there is growing evidence of a transforming, sustaining, and responsive STEM pedagogy in the AOLME approach.

Furthermore, we see the process of understanding the mathematics involved in computer programming as an essential knowledge that does not only situate the knowledge (Johri \& Olds 2011; Pea et al., 1985) within the practice of computer programming, but is also identified by the students as transformative in at-least two different ways. On the one hand, students believed the learning of binary and hexadecimal numbers, the definition of variables, and the use of the coordinate plane, to design images, as a challenging process because it was all-new to them. On the other hand, students also argued that while the new mathematical knowledge is not directly related to school mathematics, due to their view of the challenging nature of this new mathematics knowledge, students gained greater confidence in themselves, and their mathematical ability to do mathematics in the classroom. Hence, almost all of them reported performing better in school mathematics. Nevertheless, while it is important to learn the mathematics to design, model, and program images and videos, it would be just as important to use mathematical ideas and content to enhance and learn computer programming knowledge. The AOLME curriculum aims to include such an approach as part of learning to represent digital images and videos. Again, such an approach will provide greater evidence for a transformative, sustaining, and responsive STEM pedagogy.

Acknowledgements First, we want to thank the students and facilitators that have participated in AOLME. They are the reason and synergy of this project. Secondly, we also want to thank Daniel Llamocca, Neritza Diaz-Cruz, and Jessica Morales for their contributions to this study. Finally, we acknowledge the support by the National Science Foundation under NSF ITEST Award \#: 1613637, 
Broadening Participation of Latinx Students in Engineering Using an Integrated Mathematics, Engineering and Computing Curriculum in Authentic, Out-of-School Environments. Any opinions, findings, and conclusions or recommendations expressed in this material are those of the author(s) and do not necessarily reflect the views of the NSF.

\section{References}

Barr, V., \& Stephenson, C. (2011). Bringing computational thinking to K-12: What is involved and what is the role of the computer science education community? ACM Inroads, 2(1), 48-54.

Beaubouef, T., \& Mason, J. (2005). Why the high attrition rate for computer science students: Some thoughts and observations. ACM SIGCSE Bulletin, 37(2), 103-106.

Canelake, S. (2011). A gentle introduction to programming using python. http://ocw.mit. edu/courses/electrical-engineering-and-computer-science/6-189-a-gentle-introduction-toprogramming-using-python-january-iap-2011/.

Celedón-Pattichis, S., LópezLeiva, C. A., Pattichis, M. S., \& Llamocca, D. (2013). An interdisciplinary collaboration between computer engineering and mathematics/bilingual education to develop a curriculum for underrepresented middle school students. Cultural Studies of Science Education, 8(4), 873-887.

Chamberlin, S. A., \& Moon, S. M. (2005). Model-eliciting activities as a tool to develop and identify creatively gifted mathematicians. Journal of Secondary Gifted Education, 17(1), 37-47.

Chapa, J., \& De La Rosa, B. (2006). The problematic pipeline: Demographic trends and Latino participation in graduate science, technology, engineering, and mathematics programs. Journal of Hispanic Higher Education, 5(3), 203-221.

Code for All. (n. d.). What we believe. Retrievable from: https://codeforall.org.

Cope, B., \& Kalantzis, M. (2009). "Multiliteracies": New literacies, new learning. Pedagogies, 4(3), $164-195$.

Defense Advanced Research Projects Agency (DARPA). (2010). Computer Science-Science, Technology, Engineering, and Mathematics (CS-STEM) Education Research Announcement (RA). DARPA-RA-10-03.

Domínguez, H., LópezLeiva, C. A., \& Khisty, L. L. (2014). Relational engagement: Proportional reasoning with bilingual Latino/a students. Educational Studies in Mathematics, 85(1), 143-160.

Dowd, A. C., Malcom, L. E., \& Macias, E. E. (2010). Improving transfer access to stem bachelor's degrees at Hispanic serving institutions through America COMPETES Act. Los Angeles, CA: University of Southern California.

Gee, J. P. (2003). What video games have to teach us about learning and literacy. New York, NY: Palmgrave-Macmillan.

Gravemeijer, K. (1997). Solving word problems: A case of modelling? Learning and Instruction, 7(4), 389-397.

Gravemeijer, K., Cobb, P., Bowers, J., \& Whitenack, J. (2000). Symbolizing, modelling, and instructional design. In P. Cobb, E. Yackel, \& K. McClain (Eds.), Symbolising and communicating in mathematics classrooms: Perspectives on discourse, tools, and instructional design (pp. 225-274). Mahwah, NJ: Lawrence Erlbaum Associates.

Gutiérrez, R. (2018). The need to rehumanize mathematics. In I. Goffney \& R. Gutiérrez (Eds.), Annual perspectives in mathematics education: Rehumanizing mathematics for black, indigenous, and latinx students (pp. 1-10). Reston, VA: National Council of Teachers of Mathematics.

Hossain, M., \& Robinson, M. G. (2012). How to motivate U.S. students to pursue STEM (Science, Technology, Engineering and Mathematics) careers. US-China Education Review, A(4), 442-451.

Jones, E., Oliphant, E., \& Peterson, P. (2014). SciPy: Open source scientific tools for python. http:// www.scipy.org/. Accessed 7 May 2018. 
Johri, A., \& Olds, B. M. (2011). Situated engineering learning: Bridging engineering education research and the learning sciences. Journal of Engineering Education, 100(1), 151-185.

Katehi, L., Pearson, G., \& Feder, M. (2009). Engineering in K-12 Education: Understanding the Status and Improving the Prospects. Washington, D.C.: National Academy of Engineering and National Research Council.

Kalantzis, M. (2006). Changing subjectivities, new learning. Pedagogies: An International Journal, $1(1), 7-12$.

Kalantzis, M., \& Cope, B. (2005). Learning by design. Melbourne, Australia: Victorian Schools Innovation Commission.

Landivar, L. C. (2013). Disparities in STEM employment by sex, race, and hispanic origin. American Community Survey Reports: U.S. Census Bureau. https://www.census.gov/prod/2013pubs/acs24.pdf.

Lesh, R., Amit, M., \& Schorr, R. Y. (1997). Using "real-life" problems to prompt students to construct conceptual models for statistical reasoning. In I. Gal \& J. B. Garfield (Eds.), The assessment challenge in statistics education (pp. 65-83). Amsterdam, Holland: IOS.

Lesh, R., \& Doerr, H. M. (2003). Beyond constructivism: Models and modelling perspectives on mathematics problem solving, learning, and teaching. Mahwah, NJ: Lawrence Erlbaum.

Lesh, R., Hoover, M., Hole, B., Kelly, A., \& Post, T. (2000). Principles for developing thought revealing activities for students and teachers. In A. E. Kelly \& R. A. Lesh (Eds.), Handbook of research design in mathematics and science education (pp. 591-645). Mahwah, NJ: Lawrence Erlbaum.

Lesh, R., \& Zawojewski, J. (2007). Problem-solving and modeling. In F. Lester (Ed.), Second handbook of research on mathematics teaching and learning (pp. 763-804). Reston, VA: NCTM.

Litzinger, T., Hadgraft, R., Lattuca, L., \& Newstetter, W. (2011). Engineering education and the development of expertise. Journal of Engineering Education, 100(1), 123-150.

Martin, D. (2006). Mathematics learning and participation as racialised forms of experience: African American parents speak on the struggle for mathematics literacy. Mathematical Thinking and Learning, 8(3), 197-229.

Miles, M., \& Huberman, A. M. (1994). Qualitative data analysis (2nd ed.). Thousand Oaks, CA: Sage Publications.

Mooney, M. A., \& Laubach, T. A. (2002). Adventure engineering: A design centered, inquiry based approach to middle grade science and mathematics education. Journal of Engineering Education, 91(3), 309-318.

National Governors Association Center for Best Practices, Council of Chief State School Officers. (2010). Common core state standards for mathematics. Washington, D.C.: Authors.

NGSS Lead States. (2013). Next generation science standards: For states, by states. Washington, DC: Achieve Inc.

Ortiz, C. J., Valerio, M. A., \& Lopez, K. (2012). Trends in Hispanic academic achievement: Where do we go from here? Journal of Hispanic Higher Education, 11(2), 136-148.

Paris, D. (2012). Culturally sustaining pedagogy: A needed change in stance, terminology, and practice. Educational Researcher, 41(3), 93-97.

Pea, R. D., Kurland, D. M., \& Hawkins, J. (1985). Logo and the development of thinking skills. In M. Chen \& W. Paisley (Eds.), Children and microcomputers: Research on the newest medium (pp. 193-317). Norwood: Ablex Publishing Corp.

Pérez, B., \& Torres-Guzmán, M. E. (2002). Learning in two worlds: An integrated Spanish/English biliteracy approach (3rd ed.). Boston, MA: Allyn and Bacon.

Psycharis, S., \& Kallia, M. (2017). The effects of computer programming on high school students' reasoning skills and mathematical self-efficacy and problem solving. Instructional Science, 45(5), $583-602$.

Reeves, T. (2011). Can educational research be both rigorous and relevant? Educational Designer, $1(4), 1-24$. 
Rogers, S. (2009, September). Rapid prototyping: A strategy to promote interest in STEM careers. Paper Presented on US-Turkey Workshop on Rapid Technologies. Accessed 16 March 2015: http://iweb.tntech.edu/rrpl/rapidtech2009/rogers.pdf.

Schleppegrell, M. J. (2007). The linguistic challenges of mathematics teaching and learning: A research review. Reading \& Writing Quarterly, 23, 139-159.

Shaughnessy, J. M. (2012). STEM: An advocacy position, not a content area. NCTM Summing Up. Accessed 7 May 2018 https://www.nctm.org/News-and-Calendar/Messages-from-the-President/ Archive/J_-Michael-Shaughnessy/STEM_-An-Advocacy-Position,-Not-a-Content-Area/.

Stein, M. K., Smith, M. S., Henningsen, M. A., \& Silver, E. A. (2000). Implementing standardsbased mathematics instruction: A casebook for professional development. New York, NY: Teachers College Press.

Strang, G. (2007). Computational science and engineering. Wellesley: Wellesley-Cambridge.

Syed, M., \& Chemers, M. M. (2011). Ethnic minorities and women in STEM: Casting a wide net to address a persistent social problem. Journal of Social Issues, 67(3), 435-441.

Szlávi, P., \& Zsakó, L. (2017). The cognitive toolkit of programming-algorithmic abstraction, decomposition-superposition. Acta Didactica Napocensia, 10(4), 33-40.

Wing, J. M. (2006). Computational thinking. Communications of the ACM, 49, 33-35.

Open Access This chapter is licensed under the terms of the Creative Commons Attribution 4.0 International License (http://creativecommons.org/licenses/by/4.0/), which permits use, sharing, adaptation, distribution and reproduction in any medium or format, as long as you give appropriate credit to the original author(s) and the source, provide a link to the Creative Commons licence and indicate if changes were made.

The images or other third party material in this chapter are included in the chapter's Creative Commons licence, unless indicated otherwise in a credit line to the material. If material is not included in the chapter's Creative Commons licence and your intended use is not permitted by statutory regulation or exceeds the permitted use, you will need to obtain permission directly from the copyright holder.

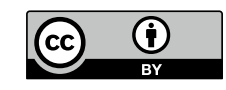

